\title{
Investigation of Asphaltene Deposition and Precipitation in Production Tubing
}

\author{
Abdolvahab Rastgoo, Riyaz Kharrat \\ Petroleum University of Technology, Ahwaz, Iran \\ Email: rastgoo68@gmail.com
}

How to cite this paper: Rastgoo, A. and Kharrat, R. (2017) Investigation of Asphaltene Deposition and Precipitation in Production Tubing. International Journal of Clean Coal and Energy, 6, 14-29. https://doi.org/10.4236/ijcce.2017.61002

Received: November 9, 2016

Accepted: January 14, 2017

Published: January 17, 2017

Copyright $\odot 2017$ by authors and Scientific Research Publishing Inc. This work is licensed under the Creative Commons Attribution International License (CC BY 4.0).

http://creativecommons.org/licenses/by/4.0/

(c) (i) Open Access

\begin{abstract}
Asphaltenes are complex molecular entities, which together with resins, aromatic hydrocarbons and saturates forms the crude oil. Asphaltenes and resins are in the thermodynamic equilibrium at static reservoir condition. However, asphaltene can precipitate due to changes in thermodynamic condition. Asphaltene deposition in production tubings has been an outstanding problem with wide economic impact on the oil industry. Meanwhile, the use of real-time tools to monitor depositions along the well is of great difficulty. In this work, the asphaltene precipitation region in a single phase flow wellbore is predicted for an oil well of the Iranian oil field. Then, asphaltene deposition thickness along the well is predicted for three time intervals. The simulation results indicated that asphaltene thickness exceeded more than $50 \%$ of tubing radius; therefore, a reduction in flow rate, an increase in pressure drop and tubing blockage are expected. Moreover, it is shown the deposits thickness along the wellbore has approximately a skew normal distribution shape, which could be the result of increases in velocity and excess pressure drop.
\end{abstract}

\section{Keywords}

Asphaltene Precipitation, Asphaltene Deposition, Wellbore, Production Decline

\section{Introduction}

Hydrocarbon crude oil is a complex mixture of hydrocarbon, hetero-atoms such as sulphur, oxygen and nitrogen as well as compounds containing metallic constituents particularly vanadium, nickel, iron and copper. The complexity of hydrocarbon fluid further increases due to the fact that its composition can vary not only with the location and the age of oil field but also with the depth of individual wells. Since petroleum comprises hundreds of molecular species, a simpler means of describing petroleum is in terms of four major fractions (based on 
their solubility and polarity): 1) saturates, 2) aromatics, 3) resins and 4) asphaltenes; known as SARA fractions. Based on this classification method, asphaltenes are the heaviest and most polar fraction of petroleum. The asphaltenes and resins have similar molecular structure but as a result of solubility based fractionation scheme employed, resins are less polar, less aromatic and have lower molar mass than asphaltenes [1]. Structural studies indicate that the asphaltene and resin molecules have a similar molecular weight ranging from 500 to $1000 \mathrm{~g} / \mathrm{mol}$. Asphaltene, however, can form aggregates with molecular-weight distribution of $10^{3}$ to $10^{5}$. These aggregates are stabilized in solution by the resins and aromatics which act as peptizing agents. When this protective shield is removed by preferential dissolution of the resin into the fluid phase, asphaltene molecules start to flocculate and aggregate into large enough particles resulting in deposition [2]. Because asphaltenes are stabilized as colloidal particles peptized by resins, any action of a chemical, electrical, or mechanical nature that de-peptize these particles will lead to flocculation and precipitation. In production systems, changes in temperature, pressure and chemical composition of crudes, combined with streaming-potential effects in well tubing, affect asphaltene stability [2].

\section{Asphaltene Precipitation}

The term deposition has often been used to describe the precipitation process. It is important to clarify the difference between the two. While the precipitation is defined as the formation of a solid phase out of a liquid phase, deposition can be described as the formation and growth of a layer of the precipitated solid on a surface. Further, a necessary but not a sufficient condition for deposition is the precipitation of a solid phase from liquid solution. Moreover, whereas the precipitation is mainly a function of thermodynamic variables such as composition, pressure, and temperature, the deposition is also dependent on the flow hydrodynamics, heat and mass transfer, and solid-solid and surface-solid interactions [3].

\subsection{Effect of Compositional Change}

Asphaltene precipitation can occur during mixing of incompatible hydrocarbon fluids, miscible flooding, $\mathrm{CO}_{2}$ flooding [4], gas lift operation using rich gases [5] [6] [7] and/or acidizing jobs. The addition of compounds with molecules that differ greatly from resins and asphaltene in terms of size and structure changes the solubility parameter [3].

\subsection{Effect of Pressure Change}

Asphaltene precipitation and deposition can also occur in oil-well tubing below the depth at which the oil becomes saturated. This phenomenon is largely ascribed to the different extents of compressibility of the light ends and the heavy components (e.g., resins and asphaltene) of the under-saturated crude. In fact, the relative volume fraction of the light ends within the liquid phase increases as the pressure of the under-saturated reservoir fluid approaches its bubble point. 
Such an effect is similar to adding a low molar mass hydrocarbon (precipitant) to a crude oil causing asphaltene de-peptization. Heavy component content in the crude oil is the main factor for the precipitation and deposition of asphaltene in the reservoir and wellbore. However, saturate components fraction and resin concentration in the crude oil also influence asphaltene precipitation. Pressure and temperature variation also affect the amount of asphaltene precipitation, decreasing the fluid pressure until bubble point pressure increases asphaltene precipitation. However, decreasing the pressure to below the bubble point pressure decreases asphaltene precipitation. In fact, pressure reduction causes more expansion in the relative volume fraction of the light components with respect to heavy components. This behavior is similar to that of adding light hydrocarbon fraction in the fluid which destabilizes asphaltene. In contrast, below bubble point pressure, the stability of asphaltene in the fluid is increased. Decreasing pressure to below bubble point, light components are evaporated and the remaining fluid becomes more asphaltene soluble. The temperature effect on asphaltene formation is not well understood thus far. Some researchers suggest that increasing temperature enhances asphaltene precipitation. However, asphaltene precipitation decreases in a two-phase condition by increasing temperature as shown by Darabi et al. [8], since light components are evaporated and asphaltene solubility increases in the remaining fluid.

In the literature, there are several approaches for modeling asphaltene precipitation such as solid model, thermodynamic solubility model [9] [10] [11] [12] [13], thermodynamic colloidal model [14], and thermodynamic miscellization model [15]. In this work, we used solid model which can be described as below.

The solid model for asphaltene precipitation was proposed based on a single-component approach. In this approach, the precipitated asphaltene is considered as a pure solid phase while the hydrocarbon fluid phases are modeled with a cubic equation-of-state (e.g. Peng-Robinson EOS) and the fugacity of the solid phase which consists of a single component can be calculated using:

$$
\ln f_{s}=\ln f_{s}^{*} \frac{\bar{v}_{s}\left(P-P^{*}\right)}{R T}
$$

where $f_{s}$ is the fugacity of solid at reservoir pressure, $f_{s}^{*}$ is the reference solid fugacity at a reference pressure $\left(P^{*}\right), \bar{v}_{s}$ is the molar volume of the solid phase and $P^{*}$ is the pressure at which the asphaltene just begins to precipitate from crude oil. The representation of the solid asphaltene precipitate as a multi-component solid phase was investigated by Thomas et al. as well. The new representation uses the solid-liquid model which was initially developed by Won [16] in order to study wax. The new model was found to be successful and also suggested some fields for further investigation and development including studying the behavior when the solvent concentration increases. MacMillan et al. [17] and Chung [18] also matched experimental data with the new multi-component solid model. The specification of large number of parameters is one of the main disadvantages of the multi-component solid model for the asphaltene precipitate [19]. 


\subsection{Asphaltene Deposition}

Asphaltene deposition in the tubing and surface facilities are the most common flow assurance issues during the production of hydrocarbon reservoirs. Applications of $\mathrm{CO}_{2}$ and light hydrocarbon gas injection have also introduced additional issues to the asphaltene formation in the reservoirs. In fact, the presence of light components in the crude oil enhances destabilization of asphaltene. Thus, asphaltene precipitation and deposition is commonly observed not only in heavy oil reservoirs, but also in conventional oil reservoirs.

Thawer et al. [2] designed a high pressure flow experiment to simulate production condition because of asphaltene deposition problem in ULA Field production facilities. Their laboratory observations were made on the regimes of deposition as a function of decreasing pressure down to and below bubble-point of live crude oil samples. During the experiment, the pressure loss that occurs in the production tubing was simulated by flowing through a variable back-pressure valve and a variety of commercially available chemicals (aromatic solvents) was used to assess and rank in order of asphaltene dissolving efficiency, which none of the blended chemicals was technically better than pure toluene and xylene. They reported asphaltene precipitation occurrence at pressure above the fluid's saturation pressure and continued till fluid's saturation pressure. Below sample's saturation pressure, deposition seemed to be stopped as a result of combination of two effects, i.e. turbulence increasing the rate of erosion and higher crude solvency.

Takhar et al. [20] used several experimental techniques to determine the asphaltene stability of a crude oil. They reported crudes with a resin to asphaltene ratio tending to unity are more likely to suffer from asphaltene precipitation than those with a ratio less that unity. They introduced a model to calculate the phase behavior by using the critical properties of the individual pure or pseudo components. Therefore, the model was calibrated with two of BPX's North Sea fields and has been conclusively shown to predict asphaltene deposition regions in production facilities.

Escobedo and Mansoori [21] studied the mechanism of migration of suspended heavy organic particles towards the walls in oil producing wells and pipelines by analyzing the diffusional effect on the solid particle deposition during turbulent flow condition. They presented a new expression of the transport coefficient for particles with different dimensionless stopping distance and reported the transport coefficient decreases with increasing crude oil kinematic viscosity. They used the deposition data from aerosols (deposition rates for aluminum and iron particles in air) to verify their model.

Kocabas et al. [22] developed a comprehensive wellbore model with all adsorption and mechanical trapping of asphaltene. The wellbore model coupled the asphaltene adsorption model with a series of phenomenological models that are independently validated with experimental and field data. The coupled mathematical model predicted permeability damage due to mechanical trapping and adsorption accurately when compared with experimental results. 
Kokal et al. [23] described the results of the study on oil samples of north Ghawar reservoir that started to show precipitation problem and ways to alleviate the deposition problem. They reported that the precipitation was linked to gas coning/cresting in the wells. In other words, the gas from the gas-cap titrates the produced oil and causes precipitation of asphaltenes that deposit in the wellbores. The data also indicated that the precipitation onset occurs at relatively low GORs.

A multiphase (oil/gas/asphaltene/water) multicomponent hydrodynamic model has been developed by Ramirez-Jaramillo et al. [24] to represent the phenomenon of asphaltene deposition in producing wells. The model is based on the assumption that asphaltene particles are thermodynamically formed at a given set of P-T-X conditions during the flow, and both molecular diffusion and shear removal are two competing mechanisms that affect the radial diffusion and consequent deposition of asphaltene particles for turbulent/laminar flows in a well. They reported that by decreasing the flow rate, the deposition layer shifts to higher depths, and vice versa. The mean width of the deposit increases slowly as the flow rate is varied, indicating that the growth rate of the deposit will remain constant independent of the flow rate. They also predicted the deposition profiles and location as a function of time.

Soulgani et al. [25] presented a new approach, based on PVT data, for thermodynamic modeling of asphaltene precipitation which has been combined with temperature and pressure of the wellbore to predict the depth of asphaltene precipitation. They used WINPROP to build a thermodynamic model of asphaltene precipitation. Then, the profile of pressure and temperature that has been measured by Production Logging Test (i.e. PLT) was combined with asphaltene precipitation curves that were generated by thermodynamic model [26] [27]. Then, they converted pressure to depth by using fluid gradient for predicting the precipitation depth. They reported asphaltene precipitation could be reduced by decreasing well head pressure or by increasing tubing size. Also increasing well flow rate causes an increase in precipitation interval in wellbore.

Vargas et al. [28] developed a simulation tool that simultaneously accounts for asphaltene precipitation, aggregation and deposition. They mentioned transport of asphaltenes in the wellbore may follow a multi-step process, including precipitation, aggregation, advection, and deposition. The rate of asphaltene precipitation was assumed to be proportional to the supersaturation degree of asphaltenes, which is defined as the difference between the actual concentration of asphaltenes dissolved in the oil and the concentration of asphaltene at equilibrium. For the case that supersaturation degree is zero, the system is right at the onset of asphaltene precipitation. They also used pseudo-first order reactions to model the aggregation and deposition stages and assumed constant diffusivity of asphaltene particles in a flow.

Eskin et al. [29] analyzed the deposition mechanism of asphaltene in pipelines based on the theoretical and experimental approach. They proposed that particle deposition on the tubing depends on particle inertia and the fluid viscosity. To 
simulate asphaltene deposition, they used the special Couette device, in which the inner cylinder rotates and particles deposit on the outer wall to measure the mass of asphaltene deposits at the different times.

Shirdel [30] studied the phase behavior and dynamic aspect of asphaltene deposition. He presented an asphaltene precipitation and deposition model into a thermal, multiphase, multi-component wellbore simulator that can be coupled with a compositional reservoir simulator. In his wellbore model, he assumed $N_{c}+$ 4 transport equation corresponding to $N_{c}$ hydrocarbon components' mass conservation plus water, liquid momentum conservation, gas momentum conservation and mixture energy conservation.

Abouie et al. [31] compared the performance of PR and PC-SAFT EOSs in both static and dynamic modeling of asphaltene phase behavior. The static results showed that both EOSs are capable of regenerating the experimental data. They proposed tuning the Peng-Robinson model based on the static results of PC-SAFT modeling to improve the prediction accuracy. Abouie et al. [32] also implemented PC-SAFT EOS into a compositional wellbore simulator and predicted the asphaltene deposition profile in the wellbore.

In this work, for the sake of simplicity, we used the same approach as Nghiem et al. [33]. So the fugacity of heaviest component, which resides in the solid phase, is calculated directly and a routine Peng-Robinson flash calculation is performed to equilibrate the fugacity of components in gas, liquid and solid phase.

\section{Results}

This section presents a case study for asphaltene precipitation and deposition in wellbore. The available PVT data is collected from a wellbore in Iranian oilfield (Fahlian reservoir) as can be seen below in Table 1 and Table 2.

In addition, Table 3 and Table 4 present the reservoir and wellbore conditions of this field, respectively.

Figure 1 shows the sketch of the wellbore subjected to asphaltene deposition in the Iranian oilfield, which is prepared by PROSPER Software. As can be seen in the figure, the wellbore depth and tubing diameter are $4337.9 \mathrm{~m}$ (14232.2 ft.) and 4.89 in., respectively.

In addition, Figure 2 shows P-T phase diagram of fluid sample. Based on the reported bottom-hole pressure and temperature, a single phase flow condition is expected in entrance of wellbore.

\subsection{Inspection of Asphaltene Precipitation}

In this work, we used the same approach as Ngheim [33] to predict the amount of asphaltene precipitation. Therefore, WinProp Software is used to evaluate the possibility of asphaltene precipitation at several pressures and temperatures. For this study, we used Peng-Robinson EOS for thermodynamic calculation of WinProp [34] [35].

The last fraction of oil components (i.e. C36+) was split into two components. The first one which is $\mathrm{C} 36 \mathrm{~A}+$ contains soluble asphaltene in oil and the other 
Table 1. Reservoir fluid composition.

\begin{tabular}{|c|c|}
\hline Component & Composition \% \\
\hline $\mathrm{N}_{2}$ & 0.07 \\
\hline $\mathrm{CO}_{2}$ & 2.26 \\
\hline $\mathrm{H}_{2} \mathrm{~S}$ & 0.22 \\
\hline $\mathrm{C} 1$ & 50.81 \\
\hline $\mathrm{C} 2$ & 8.80 \\
\hline $\mathrm{C} 3$ & 5.73 \\
\hline $\mathrm{IC}_{4}$ & 1.07 \\
\hline $\mathrm{NC}_{4}$ & 2.94 \\
\hline $\mathrm{IC}_{5}$ & 1.22 \\
\hline $\mathrm{NC}_{5}$ & 1.78 \\
\hline C6 & 2.19 \\
\hline C7 & 2.33 \\
\hline $\mathrm{C} 8$ & 2.52 \\
\hline C9 & 2.09 \\
\hline $\mathrm{C} 10$ & 1.80 \\
\hline $\mathrm{C} 11$ & 1.34 \\
\hline $\mathrm{C} 12$ & 1.18 \\
\hline $\mathrm{C} 13$ & 1.02 \\
\hline $\mathrm{C} 14$ & 0.90 \\
\hline $\mathrm{C} 15$ & 0.86 \\
\hline $\mathrm{C} 16$ & 0.72 \\
\hline $\mathrm{C} 17$ & 0.60 \\
\hline $\mathrm{C} 18$ & 0.60 \\
\hline $\mathrm{C} 19$ & 0.56 \\
\hline $\mathrm{C} 20$ & 0.52 \\
\hline $\mathrm{C} 21$ & 0.47 \\
\hline $\mathrm{C} 22$ & 0.44 \\
\hline $\mathrm{C} 23$ & 0.40 \\
\hline $\mathrm{C} 24$ & 0.37 \\
\hline $\mathrm{C} 25$ & 0.34 \\
\hline $\mathrm{C} 26$ & 0.37 \\
\hline $\mathrm{C} 27$ & 0.32 \\
\hline $\mathrm{C} 28$ & 0.29 \\
\hline C29 & 0.33 \\
\hline $\mathrm{C} 30$ & 0.29 \\
\hline C31 & 0.30 \\
\hline $\mathrm{C} 32$ & 0.26 \\
\hline Component & Composition \% \\
\hline $\mathrm{C} 33$ & 0.23 \\
\hline C34 & 0.23 \\
\hline C35 & 0.21 \\
\hline C36+ & 1.02 \\
\hline Total & 100 \\
\hline \multicolumn{2}{|c|}{ C36+ Properties } \\
\hline Density (gr/cc) & 0.93 \\
\hline MW & 491.16 \\
\hline
\end{tabular}


Table 2. PVT data.

\begin{tabular}{cc}
\hline $\mathrm{P}_{\mathrm{b}}$ (psia) & 4285 \\
\hline $\mathrm{R}_{\mathrm{s}}(\mathrm{scf} / \mathrm{STB})$ at reservoir condition & 2115 \\
$\mathrm{~B}_{\mathrm{o}}(\mathrm{rb} / \mathrm{STB})$ at reservoir condition & 1.6997 \\
Viscosity $(\mathrm{cP})$ at reservoir condition & 0.2568 \\
${ }^{\circ} \mathrm{API}$ & 44 \\
\hline
\end{tabular}

Table 3. Reservoir conditions.

\begin{tabular}{cc}
\hline $\mathrm{P}_{\text {res }}(\mathrm{psia})$ & 9206 \\
$\mathrm{~T}_{\text {res }}\left({ }^{\circ} \mathrm{F}\right)$ & 305 \\
\hline
\end{tabular}

Table 4. Flow condition in wellbore.

\begin{tabular}{cc}
\hline $\mathrm{P}_{\mathrm{bh}}(\mathrm{psia})$ & 7200 \\
$\mathrm{~T}_{\mathrm{bh}}\left({ }^{\circ} \mathrm{F}\right)$ & 290 \\
Flow Rate $(\mathrm{STBD})$ & 4845 \\
$\mathrm{P}_{\mathrm{wh}}(\mathrm{psia})$ & 3600 \\
$\mathrm{~T}_{\mathrm{wh}}\left({ }^{\circ} \mathrm{F}\right)$ & 140 \\
\hline
\end{tabular}

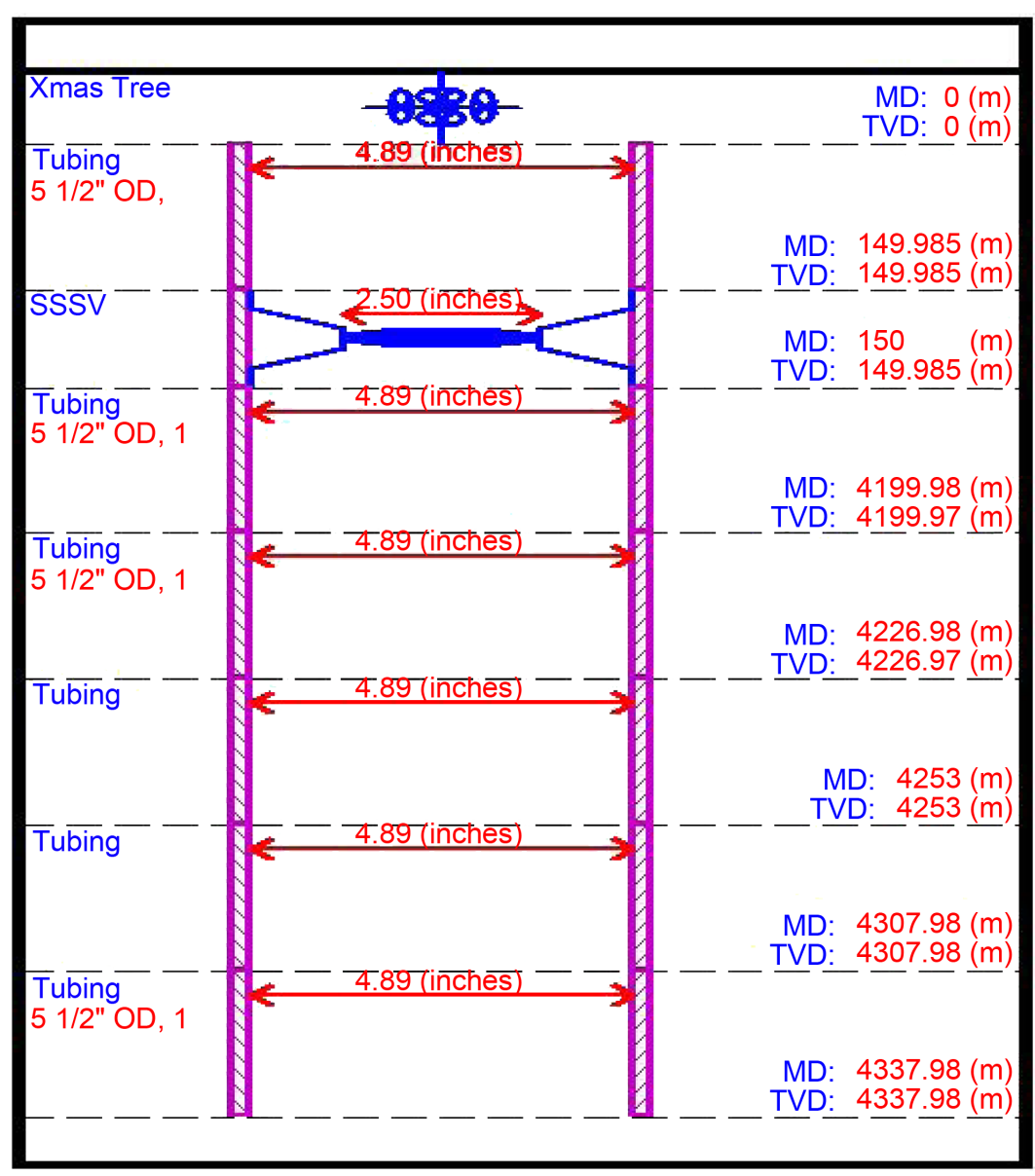

Figure 1. Sketch of case study wellbore. 


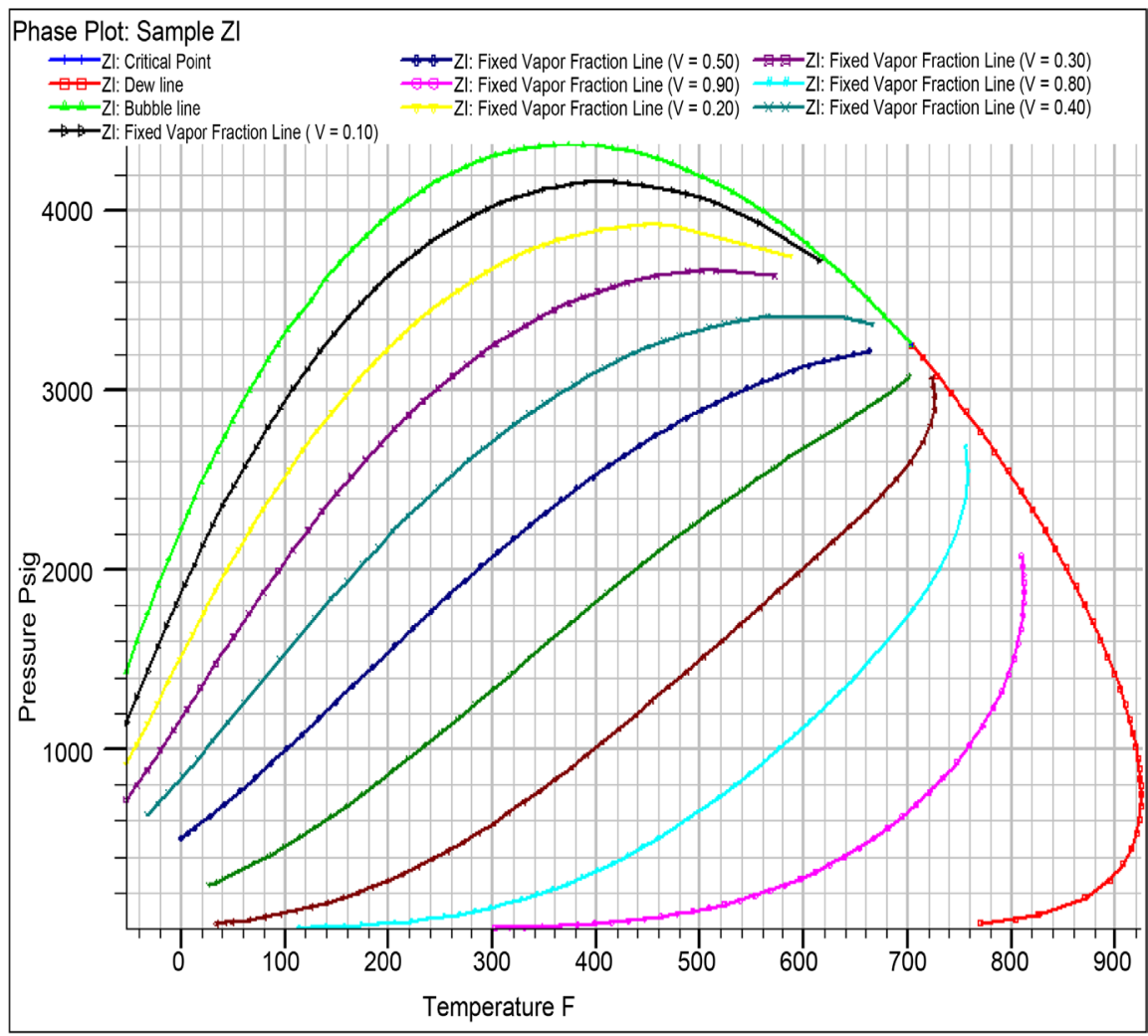

Figure 2. P-T phase diagram of reservoir oil.

one, $\mathrm{C} 36 \mathrm{~B}+$, is the precipitating asphaltene component. These two components have identical critical properties and acentric factors, but different interaction coefficients with the light components. The precipitating component has larger interaction coefficients with the light components. Higher interaction coefficients indicate that the precipitating component is more incompatible with the light components and tends to precipitate more as the amount of light component in solution increases (CMG 2007).

The relation between asphaltene in solution and precipitated asphaltene can be found (CMG 2007) by Equation (2):

$$
x_{\text {asph }} M W_{\text {asph }}=w_{\text {asph }} M W_{\text {oil }}
$$

where $x_{\text {asph }}$ is the asphaltene mole fraction, $M W_{\text {asph }}$ is the molecular weight of asphaltene, $w_{\text {asph }}$ is the asphaltene weight fraction, and $M W_{\text {oil }}$ is the molecular weight of the crude oil.

The molecular weight of residual oil is reported to be $136 \mathrm{lb} / \mathrm{lbmol}$ and the asphaltene weight percent in stock tank is reported to be $2.2 \%$. Assuming molecular weight of asphaltene to be the same as molecular weight of $\mathrm{C} 36+$, i.e. $491.16 \mathrm{lb} / \mathrm{lbmol}$, the mole fraction of precipitating asphaltene in the crude oil would be $0.609 \%$.

Next, Peng-Robinson EOS was tuned with regression on critical pressure, critical temperature and volume shift parameters of the heavier Components. After tuning, molar volume of asphaltene was set to $0.645 \mathrm{lit} / \mathrm{mol}$. Finally, the asphaltene precipitation envelope is plotted as shown in Figure 3. As can be ob- 
served, the sample has a potential for asphaltene precipitation.

\subsection{Detection of Deposition Region in Wellbore}

In this work, PROSPER Software is used to build a profile of pressure and temperature in wellbore. Then, based on Soulgani et al. method [25], the P-T profile is combined with asphaltene deposition envelope to obtain the deposition region. Figure 4 shows the asphaltene deposition envelope of the fluid sample.

Then by combining the P-T profile and asphaltene deposition envelope (shown in Figure 5), the asphaltene deposition region can be estimated. Also for the sake of simplicity, it is assumed the deposited asphatlenes only precipitate at the same region.

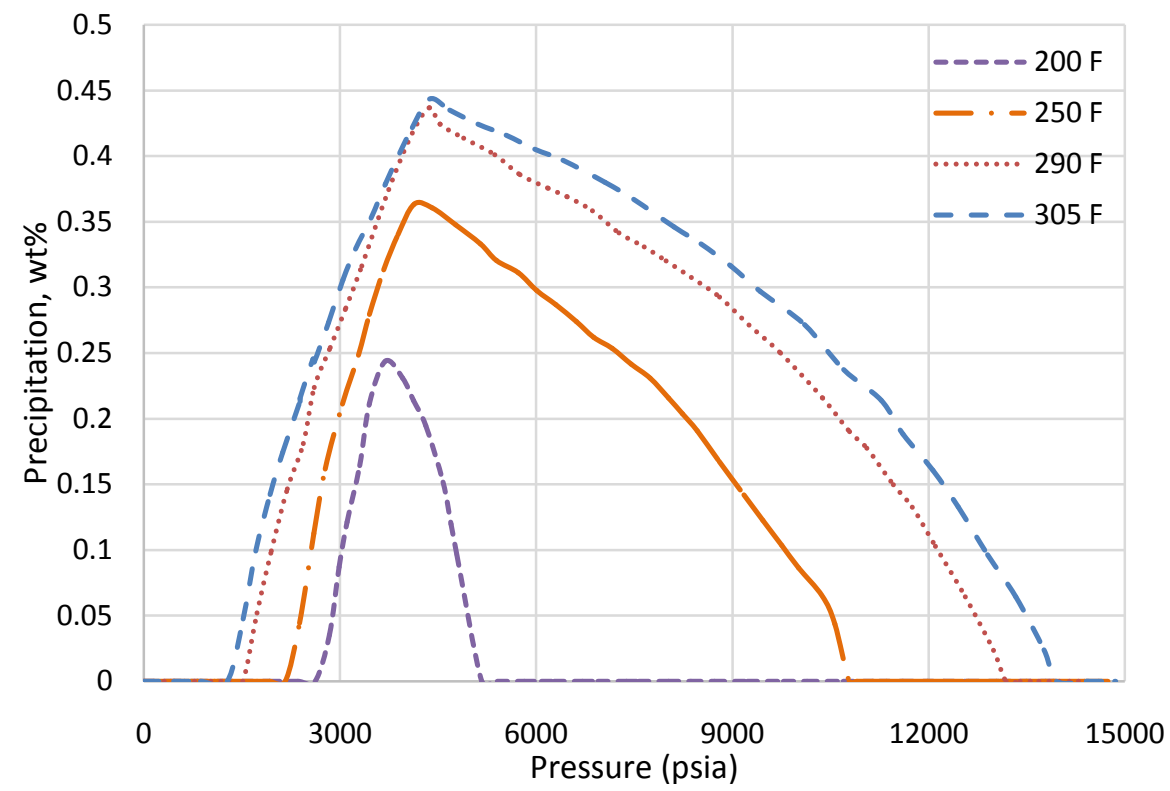

Figure 3. Asphaltene precipitation plot at different pressure and temperature.

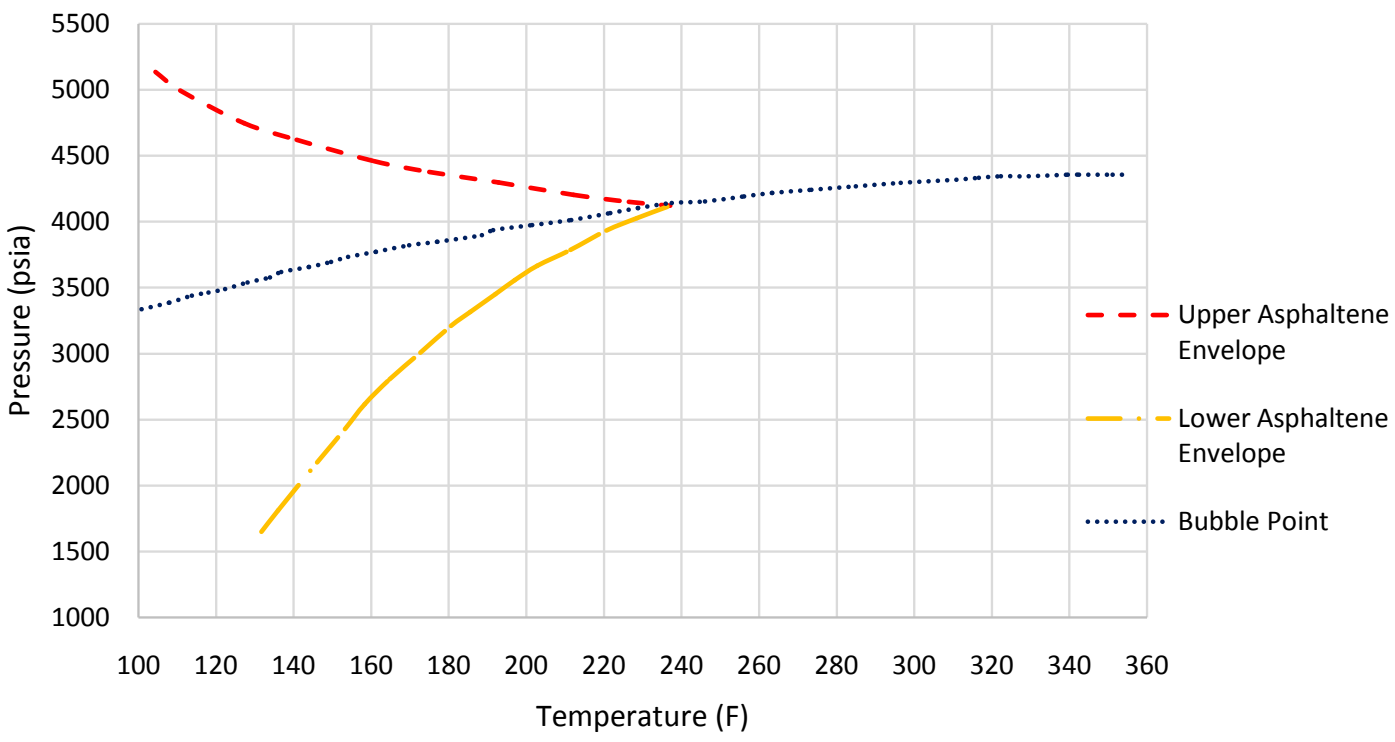

Figure 4. Asphaltene precipitation envelope. 


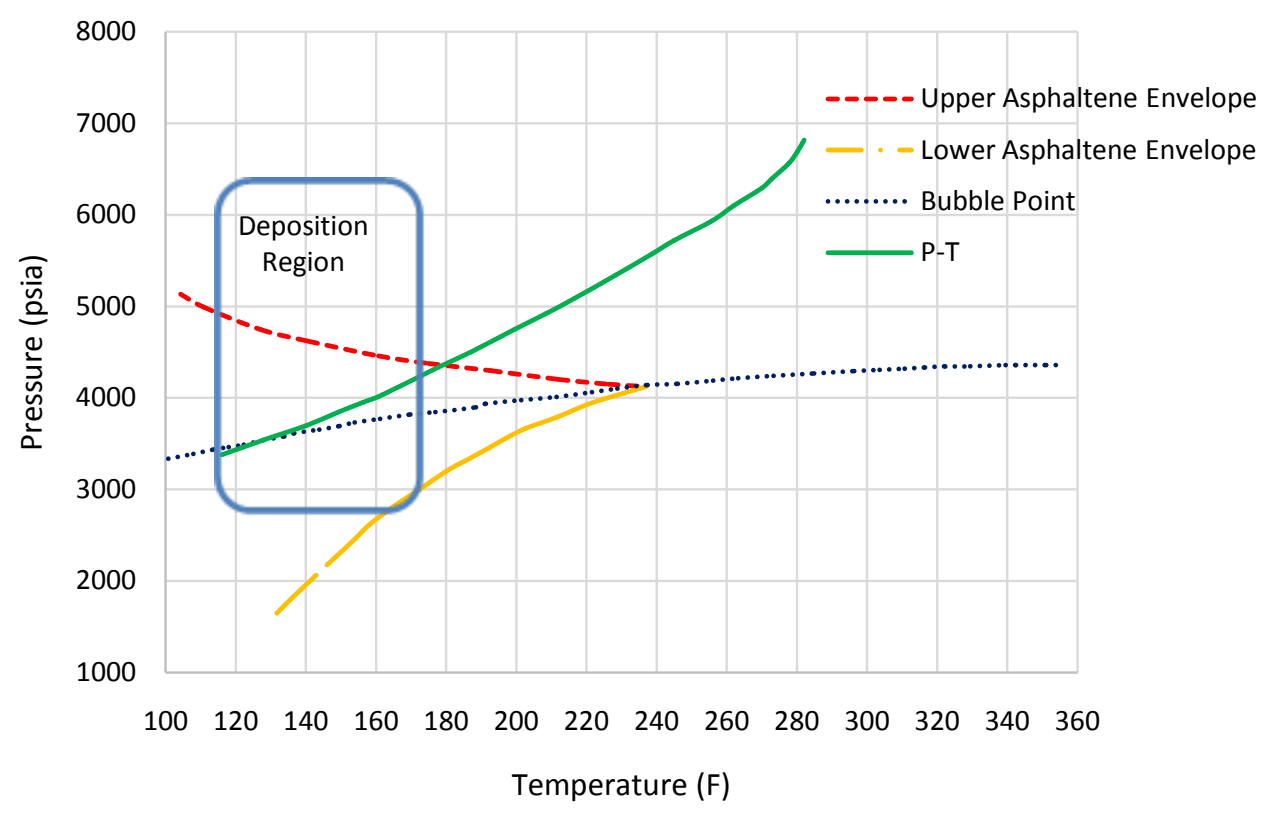

Figure 5. Combination of P-T profile and ADE in wellbore.

\subsection{Asphaltene Deposition in the Wellbore}

In the previous part, we determined the probable location of asphaltene deposition in the wellbore. Then, this region is normalized to unity and then discretized into 500 grid blocks. Then the precipitation and deposition calculations are performed based on Shirdel [30].

Figure 5 also illustrates that we have single phase flow in the wellbore and pressure and temperature of hydrocarbon mixture that enters into the deposition region, are 4340 psia and $180^{\circ} \mathrm{F}$, respectively. So the deposition region starts around the depth of 11,200 ft. In addition, the wellbore has an inner radius of 2.45 in., as it was shown in Figure 1. Productivity index of wellbore is set by PROSPER Software as shown in Figure 6. The reported flow rate is 4845 STBD or in other words, oil velocity is $4.1 \mathrm{ft}^{3} / \mathrm{s}$ at the bottom hole. The average oil heat capacity is reported to be $0.53 \mathrm{BTU} /{ }^{\circ} \mathrm{F} \cdot \mathrm{lb}$ and overall heat transfer coefficient is 5.4 BTU/ $/ \mathrm{Ft}^{2} \cdot{ }^{\circ} \mathrm{F} \cdot \mathrm{h}$.

Then, we run the simulation to evaluate the probability of asphaltene precipitation and deposition in the wellbore. Figures 7-9 show the predicted asphaltene deposition thickness after 30, 60 and 120 days, respectively. As shows in these figures, most of the deposition happens at the normalized depth of 0.3 and at the lower depth, lower deposition is observed. Note that the $\mathrm{x}$-axis is in dimensionless form of the bottom-hole depth.

Figure 10 demonstrates the comparison of deposition thickness over time. Based on the results, deposition thickness exceeded half of the wellbore radius after 120 days. So, it is expected to have a reduction in flow rate and an increase in pressure drop in the wellbore.

Moreover, the simulation results show that the asphaltene deposition has approximately a skew normal distribution shape along the wellbore as a result of increase in velocity and pressure drop. 

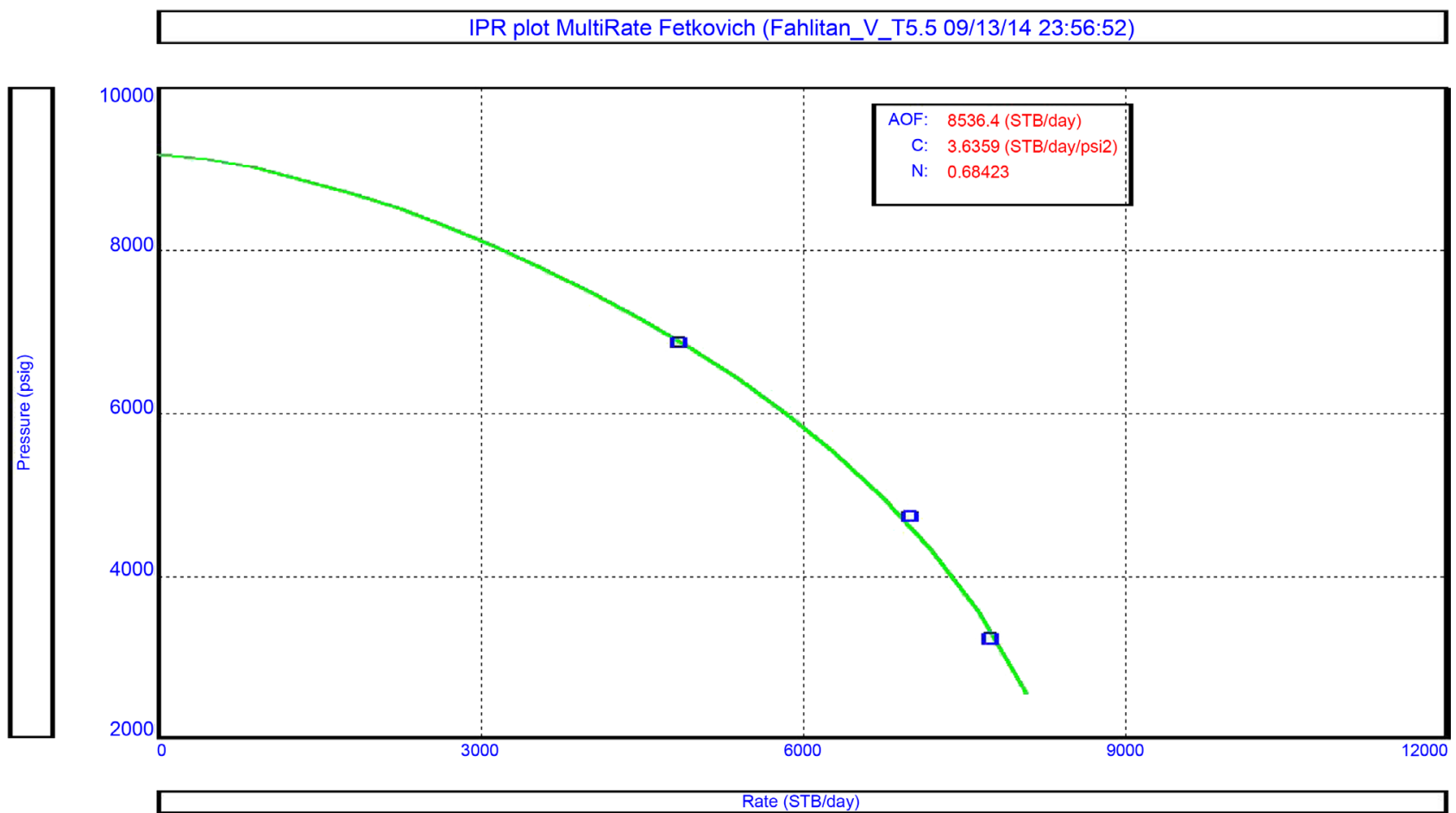

Figure 6. Productivity index of wellbore.

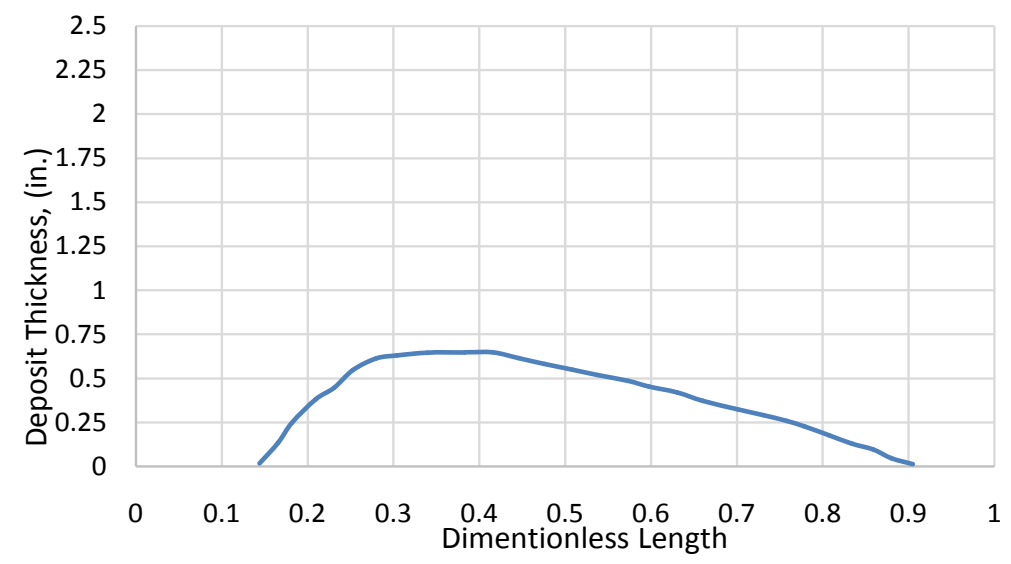

Figure 7. Deposition thickness after 30 days.

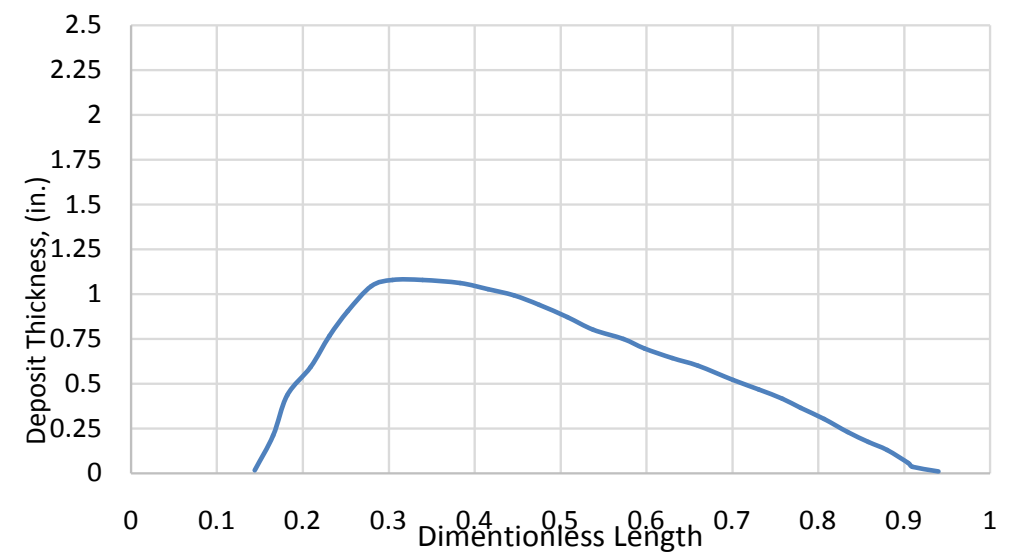

Figure 8. Deposition thickness after 60 days. 


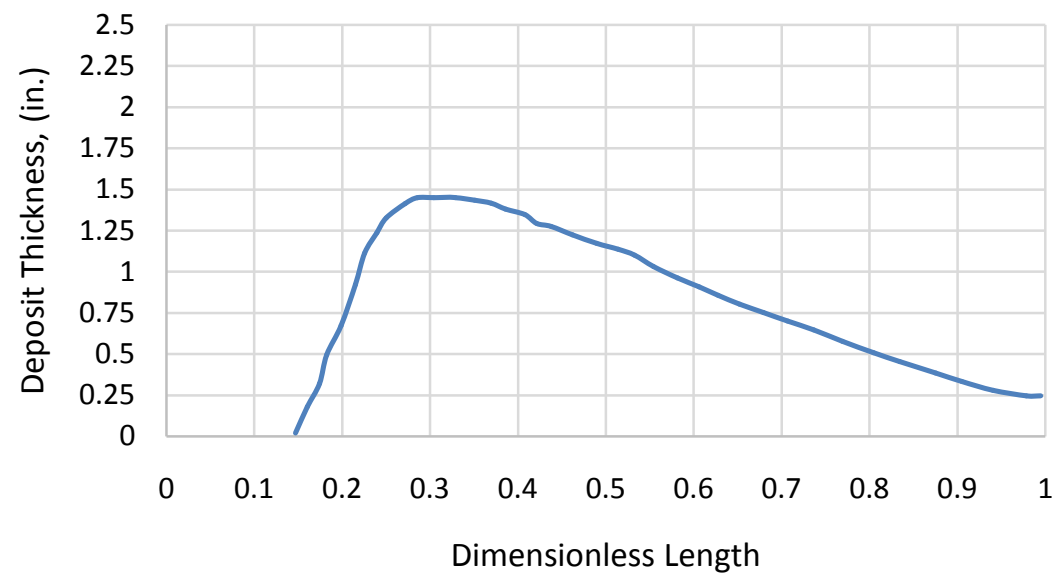

Figure 9. Deposition thickness after 120 days.

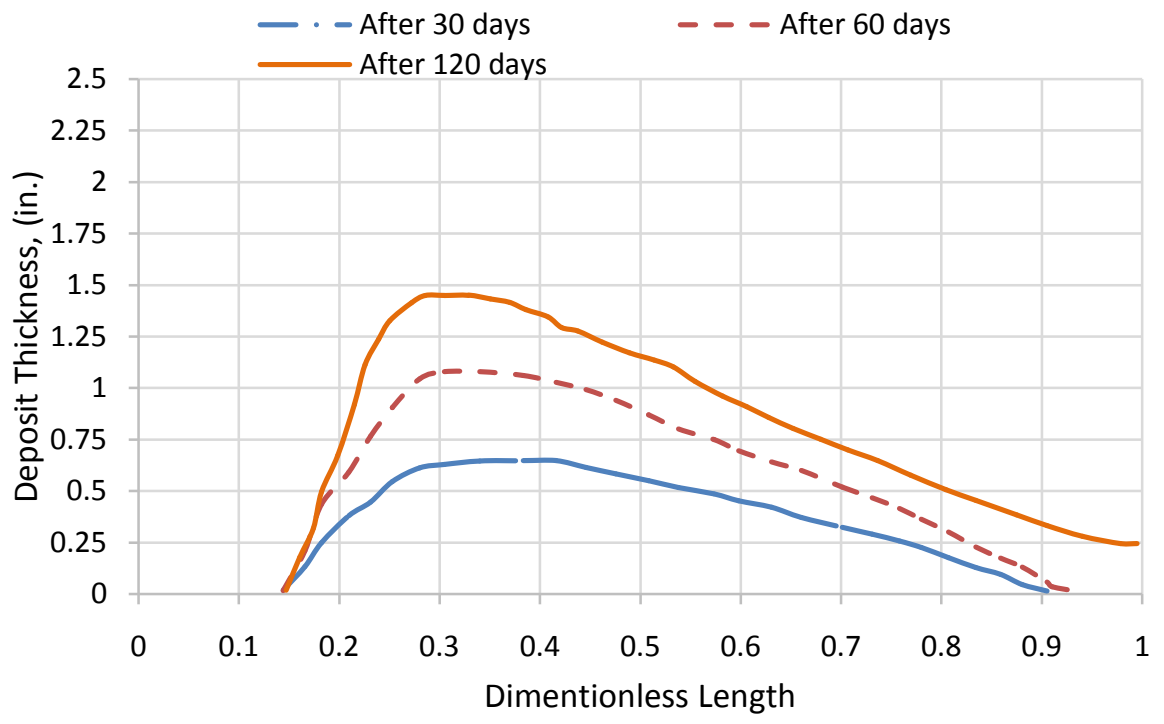

Figure 10. Comparison of deposition thickness at different times.

\section{Summary and Conclusions}

The conclusions of the study can be described as follows:

- Asphaltene precipitation and deposition region in the production wells can be predicted by the proposed approach.

- Asphaltene deposits thickness in precipitation region is calculated at different time intervals, i.e. 30, 60 and 120 days. After 120 days, deposited asphaltene thickness exceeds more than $50 \%$ of tubing radius; therefore, a reduction in flow rate, an increase in pressure drop and tubing blockage are expected.

- It is shown the deposits thickness along the wellbore has approximately a skew normal distribution shape, which could be the result of increases in velocity and excess pressure drop.

\section{References}

[1] Akbarzadeh, K., Hammami, A., Kharrat, A., Zhang, D., Allenson, S., Creek, J. and Mullins, O.C. (2007) Asphaltenes-Problematic But Rich in Potential. Oilfield Review, 19, 22-43. 
[2] Thawer, R., Nicoll, D.C. and Dick, G. (1990) Asphaltene Deposition in Production Facilities. SPE Production Engineering, 5, 475-480. https://doi.org/10.2118/18473-PA

[3] Mullins, O.C., Sheu, E.Y., Hammami, A. and Marshall, A.G. (2007) Asphaltenes, Heavy Oils, and Petroleomics. Springer, New York. https://doi.org/10.1007/0-387-68903-6

[4] Darabi, H., Abouie, A. and Sepehrnoori, K. (2016) Improved Oil Recovery in Asphaltic Reservoirs during Gas Injection. SPE Western Regional Meeting, Anchorage, Alaska, 23-26 May 2016, 14 p. https://doi.org/10.2118/180482-ms

[5] Frooqnia, A., Pishvaiea, M.R. and Aminshahidy, B. (2014) Real Time Optimization of a Natural Gas Lift System with a Differential Evaluation Method. Energy Sources, Part A: Recovery, Utilization, and Environmental Effects, 36, 309-322. https://doi.org/10.1080/15567036.2010.540631

[6] Abouie, A. (2015) Development and Application of a Compositional Wellbore Simulator for Modeling Flow Assurance Issues and Optimization of Field Production (Doctoral Dissertation).

[7] Abouie, A., Shirdel, M., Darabi, H. and Sepehrnoori, K. (2015) Modeling Asphaltene Deposition in the Wellbore during Gas Lift Process. SPE Western Regional Meeting, Garden Grove, California, 27-30 April 2015, 20 p. https://doi.org/10.2118/174067-MS

[8] Darabi, H., Abouie, A. and Sepehrnoori, K. (2016) Effect of Temperature Variations on Asphaltene Dynamics in Oil Reservoirs. SPE Western Regional Meeting, Anchorage, Alaska, 23-26 May 2016, 15 p. https://doi.org/10.2118/180481-ms

[9] Hirschberg, A., DeJong, L.N.J., Schipper, B.A. and Meijer, J.G. (1984) Influence of Temperature and Pressure on Asphaltene Flocculation. Society of Petroleum Engineers Journal, 24, 283-293. https://doi.org/10.2118/11202-PA

[10] Andersen, S.I. and Speight, J.G. (1999) Thermodynamic Models for Asphaltene Solubility and Precipitation. Journal of Petroleum Science and Engineering, 22, 53-66. https://doi.org/10.1016/S0920-4105(98)00057-6

[11] Burke, N.E., Hobbs, R.E. and Kashou, S.F. (1990) Measurement and Modeling of Asphaltene Precipitation (Includes Associated Paper 23831). Journal of Petroleum Technology, 42, 1440-1446. https://doi.org/10.2118/18273-PA

[12] Novosad, Z. and Costain, T.G. (1990) Experimental and Modeling Studies of Asphaltene Equilibria for a Reservoir under $\mathrm{CO}_{2}$ Injection. SPE Annual Technical Conference and Exhibition, New Orleans, 23-26 September 1990.

[13] Kawanaka, S., Park, S.J. and Mansoori, G.A. (1991) Organic Deposition from Reservoir Fluids: A Thermodynamic Predictive Technique. SPE Reservoir Engineering, 6, 185-192. https://doi.org/10.2118/17376-PA

[14] Leontaritis, K.J. and Mansoori, G.A. (1987) Asphaltene Flocculation during Oil Production and Processing: A Thermodynamic Collodial Model. SPE International Symposium on Oilfield Chemistry, San Antonio, 4-6 February 1987, 149-158. https://doi.org/10.2118/16258-ms

[15] Pan, H. and Firoozabadi, A. (1998) Thermodynamic Micellization Model for Asphaltene Aggregation and Precipitation in Petroleum Fluids. SPE Production \& Facilities, 13, 118-127. https://doi.org/10.2118/36741-PA

[16] Won, K.W. (1986) Thermodynamics for Solid Solution-Liquid-Vapor Equilibria: Wax Phase Formation from Heavy Hydrocarbon Mixtures. Fluid Phase Equilibria, 30, 265-279. https://doi.org/10.1016/0378-3812(86)80061-9

[17] MacMillan, D.J., Tackett Jr, J.E., Jessee, M.A. and Monger-McClure, T.G. (1995) A 
Unified Approach to Asphaltene Precipitation: Laboratory Measurement and Modeling. Journal of Petroleum Technology, 47, 788-793. https://doi.org/10.2118/28990-PA

[18] Chung, T.H. (1992) Thermodynamic Modeling for Organic Solid Precipitation. SPE Annual Technical Conference and Exhibition, Washington DC, 4-7 October 1992, 869-878. https://doi.org/10.2118/24851-ms

[19] Nghiem, L.X., Hassam, M.S., Nutakki, R. and George, A.E.D. (1993) Efficient Modelling of Asphaltene Precipitation. SPE Annual Technical Conference and Exhibition, Houston, 3-6 October, 1993.

[20] Takhar, S., Ravenscroft, P.D. and Nicoll, D.C.A. (1995) Prediction of Asphaltene deposition during Production-Model Description and Experimental Details. SPE European Formation Damage Conference, Hague, 15-16 May 1995, 311-316. https://doi.org/10.2118/30108-ms

[21] Escobedo, J. and Mansoori, G.A. (1995) Solid Particle Deposition during Turbulent Flow Production Operations. SPE Production Operations Symposium, Oklahoma City, 2-4 April 1995, 439-446. https://doi.org/10.2118/29488-ms

[22] Kocabas, I., Islam, M.R. and Modarress, H. (2000) A Wellbore Model for Field-Scale Modeling of Asphaltene Plugging. Journal of Petroleum Science and Engineering, 26, 19-30. https://doi.org/10.1016/S0920-4105(00)00017-6

[23] Kokal, S., Al-Ghamdi, A. and Krinis, D. (2003) Asphaltene Precipitation in High Gas-Oil Ratio Wells. Middle East Oil Show, Bahrain, 9-12 June 2003, 11 p. https://doi.org/10.2118/81567-ms

[24] Ramirez-Jaramillo, E., Lira-Galeana, C. and Manero, O. (2006) Modeling Asphaltene Deposition in Production Pipelines. Energy \& Fuels, 20, 1184-1196. https://doi.org/10.1021/ef050262s

[25] Soulgani, B.S., Tohidi, B., Rashtchian, D. and Jamialahmadi, M. (2008) Modelling of Asphaltene Precipitation in Well Column of Iranian Crudes: Kuapl Case Study. Canadian International Petroleum Conference, Calgary, 17-19 June 2008.

[26] Frooqnia, A., Torres-Verdín, C., A-Pour, R., Sepehrnoori, K., and Mohebbinia, S. (2013) Estimation of Near-Wellbore Relative Permeability from Numerical Simulation and Inversion of Time-Lapse Multi-Phase Production Logs. SPWLA 54th Annual Logging Symposium, New Orleans, 22-26 June 2013.

[27] Frooqnia, A., Verdín, C.T. and Sepehrnoori, K. (2016) Inference of Rock PressureProduction Properties from Gas-Oil Production Logs. Journal of Natural Gas Science and Engineering, 36, 124-143. https://doi.org/10.1016/j.jngse.2016.10.018

[28] Vargas, F.M., Creek, J.L. and Chapman, W.G. (2010) On the Development of an Asphaltene Deposition Simulator. Energy \& Fuels, 4, 2294-2299.

https://doi.org/10.1021/ef900951n

[29] Eskin, D., Ratulowski, J., Akbarzadeh, K. and Pan, S. (2011) Modelling Asphaltene Deposition in Turbulent Pipeline Flows. The Canadian Journal of Chemical Engineering, 89, 421-441. https://doi.org/10.1002/cjce.20507

[30] Shirdel, M. (2012) Development of a Coupled Wellbore/Reservoir Simulator for Damage Prediction and Remediation. SPE Annual Technical Conference and Exhibition, San Antonio, 8-10 October 2012.

[31] Abouie, A., Darabi, H. and Sepehrnoori, K. (2016) Data-Driven Comparison between Solid Model and PC-SAFT for Modeling Asphaltene Precipitation. Offshore Technology Conference, Houston, 2-5 May 2016. https://doi.org/10.4043/26881-MS

[32] Abouie, A., Rezaveisi, M., Mohebbinia, S. and Sepehrnoori, K. (2016) Static and Dynamic Comparison of Equation of State Solid Model and PC-SAFT for Modeling 
Asphaltene Phase Behavior. SPE Western Regional Meeting, Anchorage, 23-26 May 2016, 22 p. https://doi.org/10.2118/180480-ms

[33] Nghiem, L.X., Kohse, B.F., Ali, S.M. and Doan, Q. (2000) Asphaltene Precipitation: Phase Behaviour Modelling and Compositional Simulation. SPE Asia Pacific Conference on Integrated Modelling for Asset Management, Yokohama, 25-26 April 2000, 14 p. https://doi.org/10.2118/59432-ms

[34] Peng, D.Y. and Robinson, D.B. (1976) A New Two-Constant Equation of State. Industrial \& Engineering Chemistry Fundamentals, 15, 59-64.

https://doi.org/10.1021/i160057a011

[35] CMG Group (2007) Win Prop Manual.

\section{Scientific Research Publishing}

Submit or recommend next manuscript to SCIRP and we will provide best service for you:

Accepting pre-submission inquiries through Email, Facebook, LinkedIn, Twitter, etc. A wide selection of journals (inclusive of 9 subjects, more than 200 journals)

Providing 24-hour high-quality service

User-friendly online submission system

Fair and swift peer-review system

Efficient typesetting and proofreading procedure

Display of the result of downloads and visits, as well as the number of cited articles

Maximum dissemination of your research work

Submit your manuscript at: http://papersubmission.scirp.org/

Or contact ijcce@scirp.org 